\title{
Effects of Different Fluids Properties on Cavitation Performance in Centrifugal Pump
}

\author{
Saad Ghidhan ${ }^{1 *}$, Moamar Hamed ${ }^{1}$, Mansor Benaros ${ }^{2}$ \\ ${ }^{1}$ Mechanical and Industrial Engineering Department, College of Engineering, Elmergib \\ University, Libya \\ ${ }^{2}$ Mechanical and Industrial Engineering Department, Alasmarya University, Libya \\ DOI: https://doi.org/10.21467/proceedings.4.9 \\ * Corresponding author email: saadgedan@yahoo.com
}

ABSTRACT

Cavitation, which is the formation and collapse of vaporous cavities in flowing liquids, can degrade the performance of pumps and other hydraulic equipment. The aims of the present research are to investigate the effect of different fluids properties on pump cavitation performance. Consideration is given to examine the effect of liquid viscosity and density on cavitation behavior. Experimental results are presented for a centrifugal pump operating in water, kerosene and diesel fuel with different disposal rates of flow. With references to the results, the water has affected by the cavitation at less Net Positive Suction Head (NPSH) than other liquids, also it can be conducted that the kerosene shares the closest cavitation behavior with diesel fuel. Therefore, the stress produced by cavitation bubbles decreases with increase of viscosity of the liquid.

Keywords: Water, kerosene, diesel fuel, cavitation performance, centrifugal pump, Net Positive Suction Head (NPSH)

\section{Introduction}

When a centrifugal pump handles liquids with different viscosity and specifications, there Net Positive Suction Head (NPSH) normally will be different. The simple definition of the NPSHA is the difference between pressure at the suction of the pump and the vapour pressure for the liquid being pumped [1]. An increase or decrease of NPSH will result in cavitation taking place in the pump. In result, the pump will be subject to abnormal operations, such as loud noise, violent vibration, performance degradation, impeller or other components damage. In fact, measuring or predicting NPSH of a centrifugal pump at various operating conditions is quite important for the hydraulic design optimization and engineering application when the pump handles different viscous liquids and it's important to know the situation of operating with this phenomena and how to avoid the problem of cavitation [2].

In almost of petroleum industries and chemical operations pumps will deal with liquids which have such different specifications, there are two sorts of liquid products, which need to be transported by centrifugal pumps. One kind of liquid is with a higher vapour pressure but with

(C) 2018 Copyright held by the author(s). Published by AIJR Publisher in Proceedings of First Conference for Engineering

Sciences and Technology (CEST-2018), September 25-27, 2018, vol. 2 .
This is an open access article under Creative Commons Attribution-NonCommercial 4.0 International (CC BY-NC 4.0) license, which permits any non-commercial use, distribution, adaptation, and reproduction in any medium, as long as the original work is properly cited. ISBN: 978-81-936820-6-7 
Effects of Different Fluids Properties on Cavitation Performance in Centrifugal Pump

nearly the same viscosity of water, and the other kind of liquid is with a lower vapour pressure but a higher viscosity than water [3].

Many researchers [4] [5] have discussed the inception of cavitation through the experiments and numerical simulations. The phenomena of cavitation are usually determined by the value of (NPSH). The physical properties of the liquid, its vapour and the flow conditions can affect the cavitation process and thus the cavitation performance of hydraulic equipment as well. The effects of the fluid properties, flow conditions, and heat transfer can improve cavitation performance for certain liquids and/or liquid temperatures, the net positive suction head (NPSH) requirements can be significantly less than that obtained for room-temperature water. As mentioned above NPSH is defined as the total pressure above vapour pressure at the inlet to a pump This improvement (decrease) in inlet pressure requirements is attributed to the varying degrees of evaporative cooling associated with the cavitation process. Because of the evaporative cooling, the cavity pressure and the vapour pressure of the liquid adjacent to the cavity are decreased relative to the vapour pressure of the bulk liquid. This decrease in cavity pressure retards the rate of further vapour formation, thereby allowing the pump to operate at lower values of NPSH than would otherwise be possible.

The NPSH requirement for a pump operating at a given head rise and flow condition is reduced by the amount corresponding to the decrease in cavity pressure. The accurate prediction of thermodynamic effects of cavitation is therefore essential to an optimum flow system that is designed to operate with cavitation.

\section{Experimental Work}

To determine the effect of fluid viscosity on the performance of centrifugal pumps and the phenomenon of cavitation which usually occur and negatively affect the performance of these pumps as explained previously. Laboratory experiments were carried out on a centrifugal pump using different liquids (water, kerosene and diesel fuel)

\subsection{Test Rig Facilities}

There are various ways to design the test rig to study the cavitation. The most important feature of any test-rig is the means of introducing cavitation into the pump system. In this research, the closed loop configuration was chosen for this testing as indicated in a schematic diagram shown in Figure 1. The flow system consists of 1 hp centrifugal pump using DC current motor, the flow orifice meter, pressure measuring devices, suction and delivery pipelines, speed control unit, and valves. Connecting pipes and control valves are assembled with (1 in) diameter plastic connections.

The suction line consists of a tube connected to a valve that controls the flow rate and a pressure gauge connection, at the end there is a nozzle valve.

The discharge line contains a valve that controls the flow rate and a connection pressure gauge and the orifice meter to measure the flow rate. 


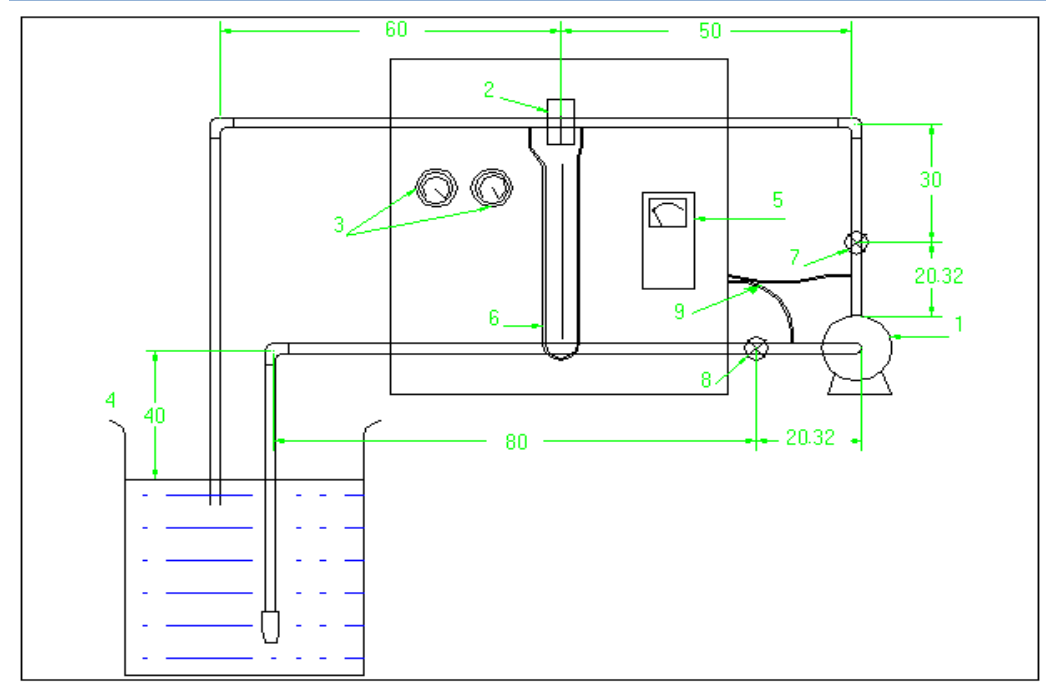

Figure 1: Schematic diagram of test rig [6].

Measuring devices are divided into, pressure gauge for the suction line and is used to measure the pressure of the water in the suction line from the type of tube Borden range from (0 to bar1) and the rate of $(0.2 \mathrm{bar})$, the pressure gauge of the discharge line is also used to calculate the pressure of the water in the line using the Borden tube, measured from ( 0 to 6 bar). The other measuring devices are power measuring device; the capacity of the pump can be measured by a Watt meter where it is connected to the pump. This device is read from 0 to $1000 \mathrm{~W}$ and is rated at $2 \mathrm{~W}$.

\subsection{Test Procedures}

The test procedure was conducted by assembling the system and connecting all the measuring devices, the driving pump is firstly operated with the water to carry out the pump performance test and cavitation test, and then the same steps of test had repeated with the kerosene and the diesel, each test has been carried out at different values of flow rate ratios.

The cavitation test on the pump has been carried out by keeping the pump running at the required speed, and flow rate ratio, and then reducing the inlet pressure step by step until the inception condition occurred. At each step, the flow rate was adjusted through the delivery valve, then the inlet pressure further reduced until developed cavitation and fall off head and efficiency was noticed. At each setting of inlet pressure and inception condition, the measurements of suction and discharge pressures and flow rate were recorded. The NPSH at each condition was calculated using the following equation: $N P S H=\left(\frac{P_{s g}}{\gamma}+\frac{V_{s}^{2}}{2 g}\right)-\frac{P_{v}}{\gamma}$ also the head of the pump was calculated by the following equation: $=\left(\frac{P_{d}-P_{s}}{\gamma}\right)+0.24$, efficiency of the pump was calculated by $\eta=\frac{\rho \mathrm{gQH}}{\mathrm{P}}$ where $\rho$ is density of the water, Q water flow rate, $\mathrm{H}$ head of the pump and $\mathrm{P}$ power [5].

Proceedings of First Conference for Engineering Sciences and Technology (CEST-2018), vol. 2 
Effects of Different Fluids Properties on Cavitation Performance in Centrifugal Pump

\section{Results and Discussion}

In order to study the performance of the pump and also to examine the cavitation in the tested pump, three tests have been done, each test was conducted with different liquid, the first test the pump used the water and all the measurements have been taken with different flow rates, then the same procedures have been done for Kerosene and diesel.

\subsection{Water Test}

Firstly the performance of the pump was studied experimentally at different flow rates, the first test was conducted using the water, in this test the flow rate has been changed from $0.389 \mathrm{~L} / \mathrm{s}$ to $1.4555 \mathrm{~L} / \mathrm{s}$, suction valve was totally opened and the level of the water in the tank was $40 \mathrm{~cm}$ from the centre of the pump.

Figure 2 presents the performance curves for the pump include power, head, efficiency and the NPSH. From Figure 2 it can be seen that the head of the pump starts decreasing with the increases of the flow rate, on the other hand the efficiency curve increase with increasing the flow rate until reached the maximum value of $26.1505 \%$ then the efficiency start to drop, the NPSH was decreased with increasing of the flow rate and finally the power has risen with dropping the flow rate.

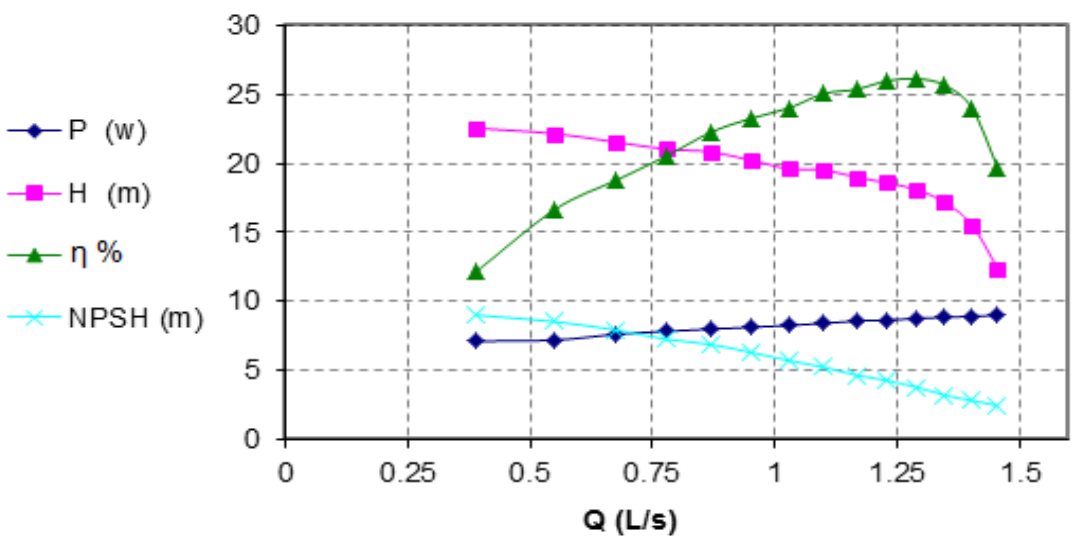

Figure 2: The performance curves for the pump for water test

Figure 3 shows the curves of NPSH at different flow rates. It can be noted that NPSH reach the collapse state, the point at which the lifting mark drops suddenly. It can be seen that, in the case of flow rate $(\mathrm{Q}=0.30 \mathrm{~L} / \mathrm{s})$ the collapse occurs at the tenth point of the suction valve gradient when the net positive clouds $(2.8693 \mathrm{~m})$ and in the case of flow rate $(\mathrm{Q}=0.60 \mathrm{~L} / \mathrm{s})$, the collapse occurs at the eighth point of the pull valve gradient when the net positive clouds $(3.4282) \mathrm{m}$ ), as well as in the case of flow rate $(\mathrm{Q}=0.90 \mathrm{~L} / \mathrm{s})$, these means the drops of the cavitation may occurs at different points with different flow rates. 


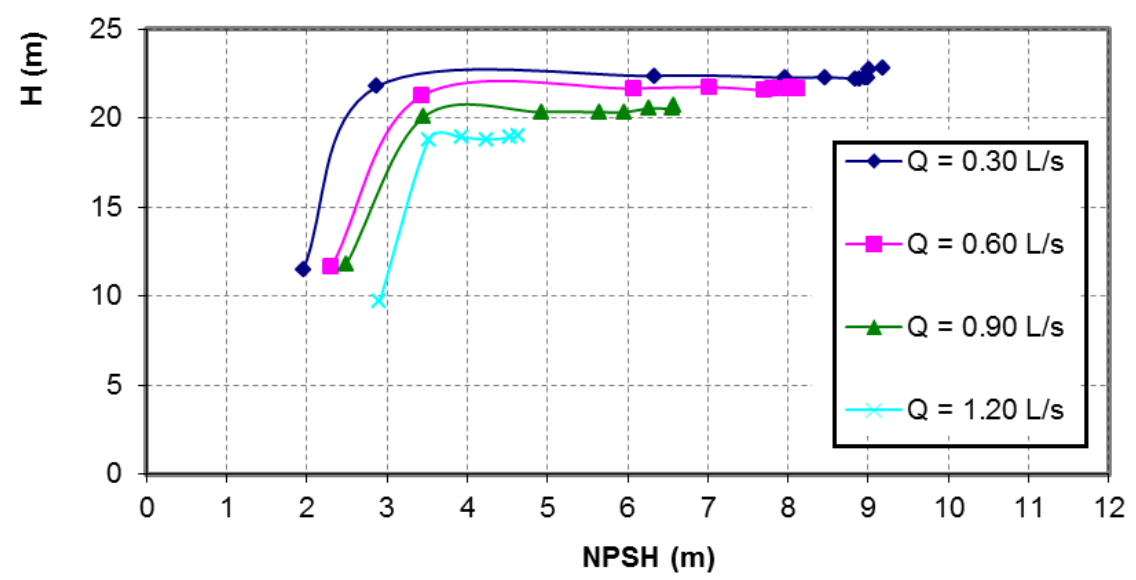

Figure 3: NPSH with different flow rate for water test

\subsection{Kerosene Test}

In this test the liquid in the test tank was changed to the kerosene, in order to study the performances of the pump and the cavitation. Figure 4 shows the performance curve of the centrifugal pump, it can be noted that, fluid starts to decrease as the flow rate and efficiency curve increases at a flow rate of $(1.167 \mathrm{~L} / \mathrm{s})$. After that, the efficiency begins to decrease.

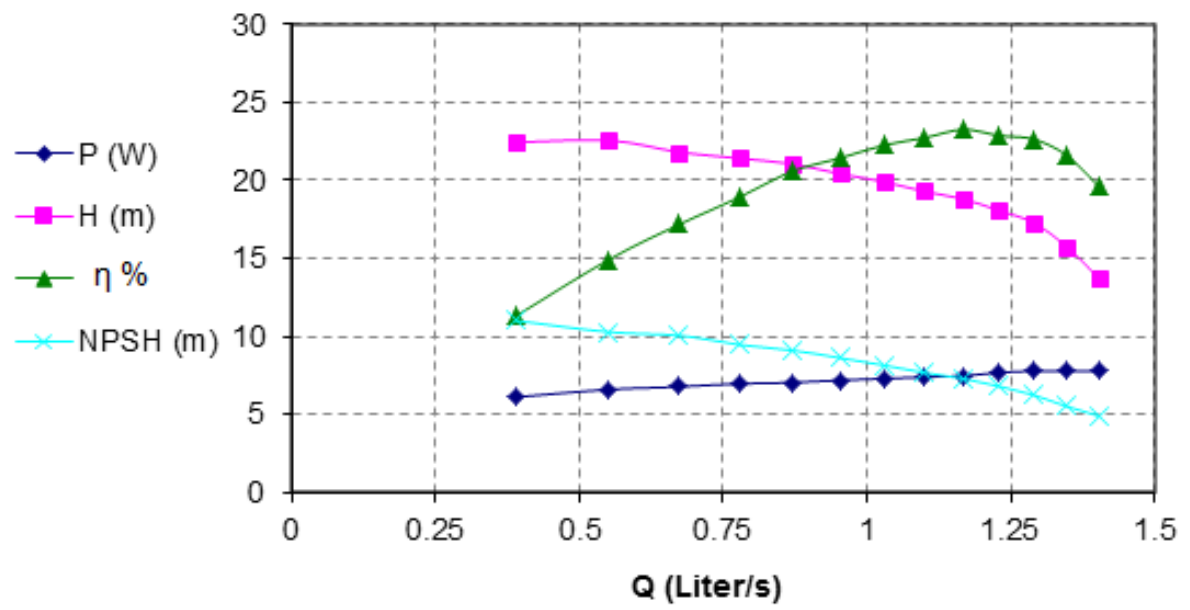

Figure 4: Performance curves for the pump for Kerosene test

Figure 5 shows the curves of NPSH at different flow rates. It can be noted that NPSH reach the collapse state, the point at which the lifting mark drops suddenly. It can be seen that, in the case of flow rate $(\mathrm{Q}=0.30 \mathrm{~L} / \mathrm{s})$ the collapse occurs at the tenth point of the suction valve gradient when the net positive clouds $(2.8693 \mathrm{~m})$ and in the case of flow rate $(\mathrm{Q}=0.60$ $\mathrm{L} / \mathrm{s}$ ), the collapse occurs at the eighth point of the pull valve gradient when the net positive 
Effects of Different Fluids Properties on Cavitation Performance in Centrifugal Pump

clouds $(3.4282) \mathrm{m})$, as well as in the case of flow rate $(\mathrm{Q}=0.90 \mathrm{~L} / \mathrm{s})$, these means the drops of the cavitation may occurs at different points with different flow rates.

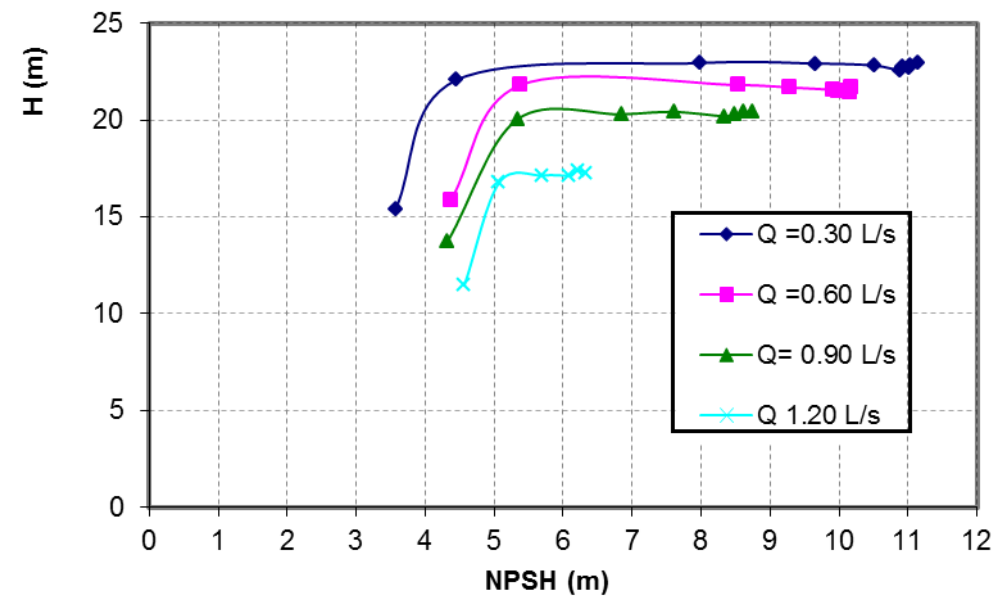

Figure 5: NPSH curves for the pump in Kerosene test

\subsection{Diesel Test}

In this test the liquid in the test tank was changed to diesel, in order to examine the effect of different viscosity on the pump performance and the cavitation. Figure 6 shows the performance curve of the centrifugal pump, it can be noted that the lifting properties begin to decrease as the flow rate and efficiency the higher the flow rate, the higher the flow rate, until it reaches its highest value $(23.0136 \%)$ at a flow rate of $1.2301 \mathrm{~L} / \mathrm{s}$.

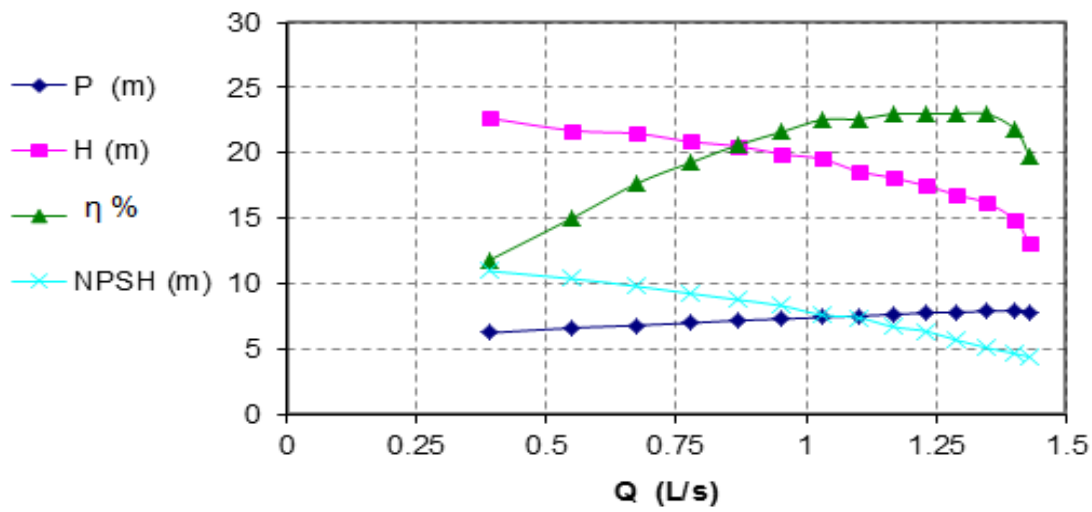

Figure 6: Performance curves of the pump for diesel with different flow rates

Figure 7 shows the curves of NPSH at different flow rates for the pump using diesel. It can be noted that NPSH reach the collapse state, the point at which the lifting mark drops suddenly. It can be seen that, in the case of flow rate $(\mathrm{Q}=0.30 \mathrm{~L} / \mathrm{s})$ the collapse occurs at the tenth point of the suction valve gradient when the net positive clouds $(2.8693 \mathrm{~m})$ and in the case of flow rate $(\mathrm{Q}=0.60 \mathrm{~L} / \mathrm{s})$, the collapse occurs at the eighth point of the pull valve gradient when the net positive clouds $(3.4282) \mathrm{m}$ ), as well as in the case of flow rate $(\mathrm{Q}=0.90$ 
L / s), these means the drops of the cavitation may occurs at different points with different flow rates.

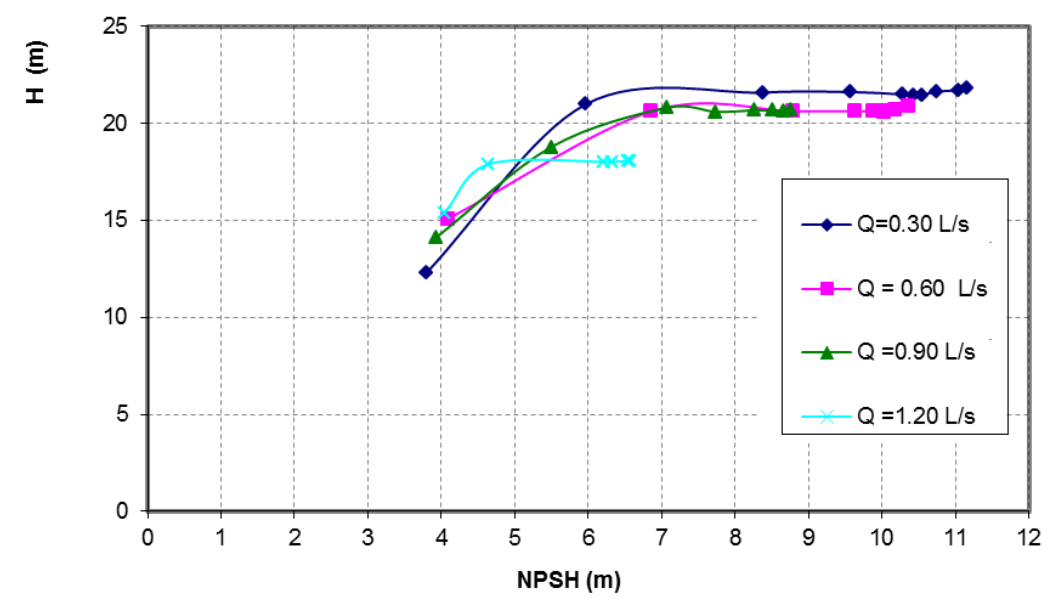

Figure 7: NPSH curves of the pump for diesel test with different flow rates

\section{Comparison of the Performance of the Pump for the Liquids Used With Different Viscosity}

The efficiency of the pump when operated with water is higher than its efficiency when operated with kerosene and diesel as shown in the Figure 8, so it is the highest efficiency in the case of water $(26.1505 \%)$ at a flow rate equal to the maximum efficiency of kerosene $(23.2624 \%)$ at a flow rate of $(1.167 \mathrm{~L} / \mathrm{s})$ and the maximum efficiency of diesel $(23.0136 \%)$ at a flow rate equal to $1.2301 \mathrm{~L} / \mathrm{s}$. The state of the water is different from the efficiency of the pump in the cases of kerosene and diesel where their efficiency is close to each other, and also finds that the difference between the efficiency of the pump at the small flow rates are close and increases as the flow rate is increased.

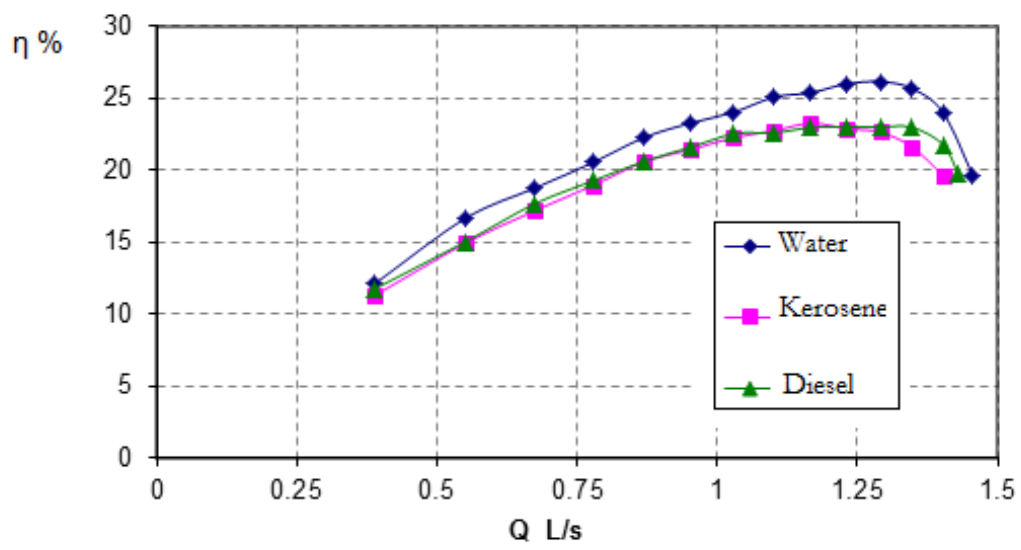

Figure 8: Efficiency curves of the pump for water, Kerosene and Diesel 
Effects of Different Fluids Properties on Cavitation Performance in Centrifugal Pump

Figure 9 shows the NPSH of the pump in the case of water, kerosene and diesel. It can be seen from the figure that the NPSH for the pump in the case of water is lower than in the case of kerosene and diesel to start in water from $(8.9964 \mathrm{~m})$ and then gradually decrease to $(2.4208)$ $\mathrm{m})$, as well as in the case of kerosene and diesel from $(11,019 \mathrm{~m}),(10.9479 \mathrm{~m})$ respectively, and then start to decrease to $(4.9136 \mathrm{~m}),(4.3899 \mathrm{~m})$, respectively.

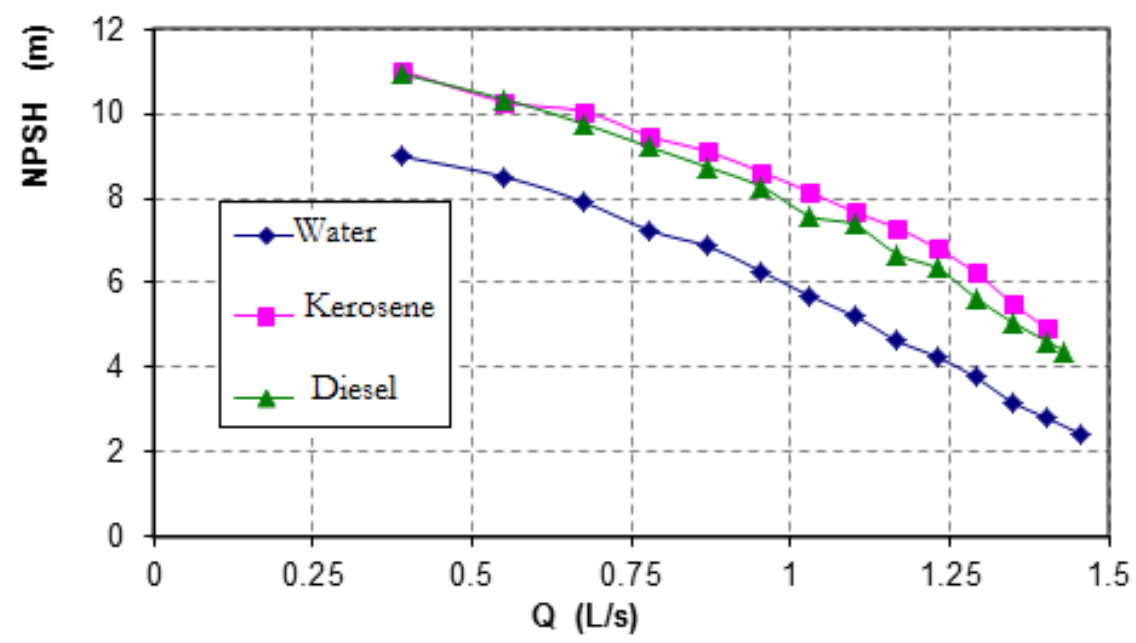

Figure 9: NPSH curves of the pump for water, Kerosene and Diesel

\section{Conclusions}

Experimental was conducted for different flow rates, and with different liquids, these results are presented for a centrifugal pump operating in water, kerosene and diesel fuel with different disposal rates of flow, to examine the effect of liquid viscosity and density on cavitation behaviour. Based on the experimental results, the water has affected by the cavitation at less Net Positive Suction Head (NPSH) than other liquids, also it can be conducted that the kerosene shares the closest cavitation behaviour with diesel fuel. Therefore, the stress produced by cavitation bubbles decreases with increase of viscosity of the liquid.

\section{References}

[1] Al-Hashmi, S, Gu, F, Li, Y, Ball, A, Fen, T and Liu, "Cavitation detection of a centrifugal pump using instantaneous angular speed," ASME $7^{\text {th }}$ Biennial Conference on Engineering Systems Design and Analysis, vol. 3 Manchester, England, July 19-22, 2004, pp. 185-190.

[2] Ahmed A. B. Al-Arabi and Sobeih M. A. Selim, "Reality of Cavitation Inception in Centrifugal Pumps," 8th Internal Conference on Sustainable Energy Technologies; Aachen, Germany $31^{\text {th }}$ August $-3^{\text {rd }}$ September, 2009, pp 1-11.

[3] Schiavello B., Visser F C, "Pump Cavitation-Various NPSHR Criteria, NPSHA Margins, and Impeller Life Expectancy," Proc. of the 25th Int. Pump Users Symp. (Houston, Tex, 23-26 Feb) 2009, pp 113-144

[4] Spraker W. A. "The Effects of Fluid Properties on Cavitation in Centrifugal Pumps." J. Eng. Power, vol. 87, no. 3, July 1965, pp. 309-318.

[5] Maxime Binama, Alex Muhirwa, Emmanuel Bisengimana. "Cavitation Effects in Centrifugal Pumps- A Review" Binama Maxime.Int Journal of Engineering Research and Applications, vol. 6, Issue 5, (Part-1) May 2016, pp.52-63.

[6] M. A. Hosien, S. M. Selim., "Experimental study of cavitation criterion in centrifugal pumps". J Visual 2013; 16:99110. 